\title{
Para una tipología de las «representaciones sociales». Una lectura de sus implicaciones epistemológicas
}

\author{
ÁNGEL CARretero \\ Universidad de Santiago de Compostela \\ angelenrique@usc.es
}

Recibido: 01.09.2009

Aceptado: 17.05 .2010

\section{INTRODUCCIÓN: LA «ACCIÓN SOCIAL» Y EL ESPECTRO DE «LO REPRESENTACIONAL»}

La revitalización sociológica de las «representaciones sociales» sólo resulta comprensible en concordancia con una particular concepción de la «acción social». El anhelo de cientificidad, inspirador de la sociología en sus orígenes, habría propiciado la adopción por parte de ésta de un modelo epistemológico explicativo-causal, siguiendo la estela de las ciencias de la naturaleza y en el contexto de una atmósfera - la de la segunda mitad del siglo XIX - marcada por una ilimitada confianza en los poderes emancipadores atesorados en la ciencia. Para ello, paralelamente, urgía consolidar un paradigma epistemológico que sirviese para fundamentar y certificar la validez de los cánones de la emergente cientificidad de lo social. Aquí, lo decisivo será, siguiendo una vez más el referente de la ciencia natural, un obsesivo esfuerzo doctrinal para lograr alcanzar un distanciamiento del «sujeto» con respecto del «objeto», para de ello derivarse finalmente una visión del conocimiento como «espejo de la naturaleza» (Rorty, 1995). Como es bien sabido, muy pronto lo social como «objeto» comenzó a revelar unas «señas de identidad» reacias a su acceso desde los criterios de cientificidad institucionalizados por el entronizado saber de las ciencias naturales. El decurso posterior del saber sociológico irá paulatinamente corroborando esta peculiar especificidad de su «objeto». El desvelamiento de la idiosincrasia de este «objeto» ha exigido desalinearse, cuando no enfrentarse, con el prototípico énfasis por explicar de las ciencias duras y una apuesta por el comprender. La «acción social» se torna como algo propiamente singularizado; $\mathrm{y}$, 
precisamente debido a ello, refractario a la legalidad propuesta desde los parámetros de la ciencia. Y aquello que, fundamentalmente, singularizará a dicha «acción social» es que ésta se encuentra inevitablemente entretejida en un horizonte propiamente «cultural» (Alexander, 2000), en unas «formas simbólicas» (Cassirer: 1972), en una «textura identitaria» (Durkheim, 1982); en definitiva, en un mundo ideacional que no sólo es un aspecto constitutivo más de la vida social sino precisamente aquello que estructura su «significación».

La sociología de corte fenomenológico primero (Schütz: 1962), y desde otro ángulo la hermenéutica (Gadamer: 1977-2002), han sido la corrientes filosófico-sociológicas contemporánea que más se ha afanado en resaltar esta «significación cultural», implicada en la «acción social», que sólo resultará accesible mediante la apertura a una metodología de índole comprensivo. La extrema particularidad del «objeto» de la ciencia social es que éste es un «sujeto», que el «objeto» lleva sobreimpreso una «subjetividad» en una constante simbiosis con el acerbo culturalmente cristalizado. Si el empeño de las ciencias duras (al menos, sin entrar en mayores matices, en su proyecto fundacional) había sido la erradicación - por subsunción- de lo más genuinamente «singular» en aras de «lo universal» (Adorno-Horkheimer, 1994), la actitud hermenéutica apostará por el reencuentro con «lo singular», con una orillada singularidad que adquirirá su autenticidad vista como experiencia culturalmente arraigada. Su intención de fondo no será otra que redescubrir que el «sujeto» no se encuentra separado del mundo, sino comprometido en éste, en su «objeto» de conocimiento; y que, por tanto, la «verdad» no cabe entenderla más que desde unas claves «contextuales» y en términos «pragmáticos» (Joas, 1998). La «acción social» se inscribe, pues, en un «marco de significaciones» socialmente compartido, por lo que el desciframiento de su lógica debe recurrir a una «interpretación». Este «mundo significativo» (Berger-Luckmann: 1986), soportado más sobre un sedimentado y enquistado «pre-juicio» que sobre la transparencia lógico-racional del «juicio» (Gadamer, 1977), resultará algo impenetrable para una epistemología positivista consagrada a la objetividad; asimismo, será también aquello que catapultará una revalorización de la trascendencia del espectro de las «representaciones sociales» en la trama social.

Pero además, íntimamente ligado lo anterior, esta reconsideración de la «acción social» enmarcada en el contexto de «lo representacional» nos facilita el esclarecimiento de unos rasgos definitorios de ella escurridizos para un programa metodológico sustentado sobre bases positivistas; obligándonos a reconocer el aspecto más estrictamente «cualitativo» de la «acción social»y, por consiguiente, a asumir una metodología, también lógicamente «cualitativa», acorde a ello.

(1) Por una parte, en toda «acción social» se inscribe y se proyecta un «sentido». La indigencia de «sentido» y el ansia por colmar esta indigencia, propios de la condición humana, sólo será colmada en el marco de unas sólidas «representaciones colectivas», en un «nomos a-problematizado», desde donde todo ad- 
quiere finalmente «sentido» (Berger, 1981); en unos «marcos simbólicos» suministradores de certezas para organizar los procesos psico-sociales (Geertz, 1990).

(2) Por otra parte, la «acción social» es incesantemente «creadora» de «formas culturales» nuevas, dando, así, libre curso a la irrupción de «lo nuevo» en la historia (Castoriadis, 1983) y forjando, asimismo, la cristalización de «mundos imaginarios», de «fantasías colectivas», inmunizadoras ante la incertidumbre acompañante de la vida (Bergson, 1996); en donde se nos estaría revelando, en cualquiera de sus vertientes, una insondable creatividad humana fruto de la cual emanaría el mundo de las «representaciones colectivas».

\section{APROXIMACIÓN SOCIOLÓGICA A LAS «REPRESENTACIONES SOCIALES»}

En las últimas décadas ha recobrado un inesperado auge el reconocimiento del papel del ámbito tradicionalmente denominado de «las representaciones sociales» en el estudio del funcionamiento tanto del orden como de los procesos de cambio social. En buena medida, este reconocimiento ha surgido de una demanda surgida en el interior de las ciencias sociales como reacción frente a la hegemónica institucionalización de una epistemología y metodología de acento marcadamente positivista. En el pensamiento sociológico de Emile Durkheim (2000: 27-58), pionero en la reivindicación de un estatuto estrictamente sociológico para las «representaciones sociales», todavía se conjuga la difícil tentativa por acomodar la importancia conferida a las «representaciones colectivas» como garantizadoras de un necesario cemento social en el marco de una visión eminentemente positivista de la incipiente ciencia social. En sus diferentes versiones, y más allá de sus discordancias, la revitalización epistemológica de las «representaciones sociales» en el examen de la lógica social obedece al diagnóstico según el cual el desciframiento de las claves de la realidad social exige ir más allá de una mera consideración de los fenómenos sociales como algo con una existencia entendida al modo de un dato puramente objetivo e independiente del modo en cómo el investigador se acerca a éste y, asimismo, traducible desde el espectro metodológico de unas generalizadas leyes científicas. El denominador común a las diferentes perspectivas que, de un modo u otro, han enfatizado la relevancia del orden de las «representaciones sociales» en la comprensión de la vida social es el haber explicitado la importancia, fundamentalmente epistemológica pero también metodológica, de una «invisibilidad social» profundamente reacia y resbaladiza ésta a su captación desde el modelo de saber aupado desde preceptos positivistas; la cual se revelaría, no obstante, como el oculto, aunque auténtico, fundamento explicativo de toda vida social.

Es indudable, y no debiera ser soslayado, que el tratamiento específicamente sociológico de las «representaciones sociales» ha sido, tradicionalmente, un patrimonio, sino exclusivo al menos prioritario, de la sociología francesa. Sin 
entrar por el momento en un examen detallado, recordemos no solamente, a este respecto, la propia propuesta fundacional durkheimiana, sino también los análisis de la noción de «habitus» ligada a las nociones de «capital» y «dominación simbólica» (Bourdieu, 1991) o el tratamiento que se ha hecho de las «representaciones colectivas» sobrepasando la circunscripción temática abonada a la psicología al uso (Moscovici: 1961). Las incursiones sociológicas que, en esta dirección, son llevadas a cabo en el mundo anglosajón serán de una menor amplitud, aunque, al mismo tiempo, ciertamente exitosas. Como luego veremos, en este último sí, por ejemplo, se ha acometido con gran profundidad el estudio del «imaginario social» implicado en el dominio de la epistemología científica, con la intención de introducir un por veces obviado sello social en el examen de la fundamentación de la validez de la ciencia. Sin embargo, en éste universo académico la aplicabilidad sociológica de las «representaciones sociales» no deja de ser una posición teórica, tal como antes señalábamos, un tanto menos afianzada que en la tradición francesa (probablemente debido ello a la cercanía o alejamiento del influjo despertado por la obra tardía durkheimiana, más específicamente por su visión de lo religioso como «ideación» forjadora de una «conciencia colectiva»). Especialmente provechosos son, no obstante, los estudios de Anderson (1993) en el caso del nacionalismo, Taylor (2006) para la modernidad, Thompson (1992) sobre la cultura mediática, Alexander (2000) sobre la «integración colectiva»y, especialmente, Douglas (1973) en su finísimo desvelamiento de la lógica explicativa del enraizamiento cultural de la «representación de pureza», en donde se estaría apuntando claramente a lo que luego se catalogará como una «sociología de las profundidades».

En este sentido, enfatizar la trascendencia sociológica de las «representaciones sociales» entraña reincidir en la importancia cobrada en los últimos años, especialmente en el espectro de las ciencias sociales que apuesta por la interpretación en detrimento de la explicación, por el término denominado como «imaginario social», o, en plural, los «imaginario(s) social(es)». Con la elaboración de la noción de «imaginario social», el dominio hasta entonces difuso y tradicionalmente etiquetado como el orden de las «representaciones sociales» parece convertirse en objeto de una definitiva sofisticación y profundización conceptual; sin obviar, sin embargo, los usos distintos y subyacentes a las auténticas concomitancias de fondo que pudieran hacerse de ambas nociones (Pérez Rubio, 2009: 296-298), su complementariedad (Baeza, 2008: 111), así como el acotamiento o restricción que pudiera hacerse del «imaginario social» en términos de «representación social» (Girola, 2007: 62). Noción ésta, la de «imaginario social», que ha acogido, además, múltiples lecturas y que ha sido objeto de utilización en una variada gama de escenarios del saber, desde la filosofía hasta las ciencias sociales, pasando por la psicología, el psicoanálisis, la historia y la literatura (Thomas, 1998). Precisemos que es por completo ajeno a nuestra intención, no obstante, introducirnos en el particular tratamiento que desde el psicoanálisis, y más concretamente desde el lacaniano, se ha llevado a cabo de «lo imaginario» en una complementaria vertiente tanto psíquica como social. 
Nuestro interés se centrará, prioritariamente, en abordar la radicalidad asignada al «imaginario social» en el proyecto de una sociología que se autodefine como postempirista; o, en palabras de Patrick Tacussel, diríamos que «la consideración de los procesos imaginarios en la vida social será lo que permitirá analizar los hechos y los acontecimientos sociales a través de las creencias, las representaciones y los sentimientos comunes» (Tacussel, 2000: 117).

Por otra parte, conviene apuntar que a lo largo de la historia del pensamiento occidental, el término «imaginario» - más que el de «imaginario social»- ha hecho referencia repetitiva al dominio de lo que, sin unos perfiles claramente delimitados, bien se podría identificar con el de la «fantasía», admitiendo recurrentemente un contradictorio enjuiciamiento epistemológico en términos dicotómicos de falsedad/creatividad (Vèdrine, 1990). Una referencia ésta que, como se han ocupado de recalcar (Bachelard, 1998) y (Durand, 2000), estaría incidiendo en la radicalidad de este «universo fantasioso» que anidaría permanentemente en el sustrato de toda vida tanto individual como colectiva; y cuyo origen remitiría a una condición antropológica «imaginante», abortada por las prerrogativas del «principio de realidad» dictado por la civilización occidental, si bien proyectado éste, ineludiblemente, sobre distintas formas de expresividad cultural.

En otro lugar, tratando de radiografiar los trazos característicos del universo de «lo imaginario social», distinguíamos una doble vertiente de éste: una dimensión «instituyente», ligada a la instauración de «formas culturales» emanadas de la fuerza creadora de «lo imaginario» para trascender la facticidad de lo real, y una dimensión «instituida», ligada a la legitimadora institucionalización de una cristalizada e incuestionable significación del mundo para aquellos que a aquél se adhieren (Carretero, 2008). Es indudable que la primera vertiente reporta sugerentes líneas de investigación en el campo de la antropología sociocultural, en lo relativo a la comprensión de la lógica/ilógica que preside una creatividad expandida tanto en las macrofórmulas culturales (fundamentalmente míticas y/o religiosas) como en las microfórmulas culturales diseminadas en lo cotidiano (por ejemplo, desde los dibujos animados hasta el graffiti). Pero será la segunda vertiente aquella en la que más nos interesará dirigir nuestra atención al tratar de elucidar las implicaciones epistemológicas, y consiguientemente metodológicas, del «imaginario social» en el dominio de las ciencias sociales, y más específicamente en el de la sociología.

Esta segunda vertiente, que aquí nos ocupa, había flotado en el ambiente de las ciencias humanas y sociales al menos desde comienzos de la década de los sesenta del pasado siglo, aunque en la actualidad seguiría siendo un terreno todavía inhóspito, poco explorado sociológicamente y que estaría demandando una nítida radiografía de su idiosincrasia. En este sentido, la historia del pensamiento filosófico y sociológico contemporáneo estará jalonada por un disperso conjunto de tentativas por aprehender este esencial régimen de «invisibilidad» sobre el que toma asiento lo social. Así, primero Thomas Kuhn (1986), mostrando que lo que él llamaba «ciencia normal» se sostenía sobre un «paradig- 
ma»; sobre algo no visualizable y que escapaba al privilegio de la objetividad que la ciencia clásica había adoptado como baluarte epistemológico. Luego, poco después, Michel Foucault (1968), revelando que cada modalidad de saber histórico, y más en concreto de los saberes relativos al campo de las ciencias humanas y sociales, descansaba sobre una «epistème», sobre unas aprióricas condiciones de posibilidad, siempre tácitas o implícitas, que lo sostendrían. Luego, asimismo, Sergé Moscovici (1961), (1989) y su seguidora Denise Jodelet (1986), desde la psicología social, pusieron de relieve la trascendencia, no sólo teórica sino fundamentalmente práctica, de ideaciones colectivas — lo que llamarán las «representaciones sociales»- que desempeñan, a su juicio, el papel desempeñado antaño por los grandes relatos míticos en las civilizaciones antiguas, a saber: dotar de una estructura organizada de «sentido» a la totalidad de la experiencia cotidiana. Recientemente, en la misma línea, la «sociología del conocimiento científico» propuesta actualmente por David Bloor (1998), Esther Díaz (1996) o Emmanuel Lizcano (1993), con la mirada puesta este último en la matemática, han subrayado los presupuestos de fondo («imaginarios») sobre los que reposan las construcciones teóricas y las prácticas inherentes a la actividad científica; algo, por otra parte, ya intuido a su manera con anterioridad en la noción de «obstáculo epistemológico» de Gaston Bachelard (1997). Sin olvidarnos tampoco de la relevancia epistemológica cobrada por las «representaciones sociales» a raíz de la nueva sensibilidad historiográfica inaugurada por la Escuela de Annales (Marc Bloch, Lucien Febvre, Georges Duby o Jacques Le Goff entre otros). Es digno de mención, asimismo, que, salvo en contadas excepciones, la antropología social y cultural de origen fundamentalmente francés (Balandier, 1974), (Godelier, 1990) ha sido más receptiva al esclarecimiento de la eficacia simbólica de este «mundo representacional» que la disciplina sociológica. En suma, la idea que rezumará en la preocupación temática de una constelación de autores, no sólo del abanico de las ciencias humanas y sociales sino también de las ciencias llamadas duras, es la existencia de un institucionalizado, aunque implícito, registro de «no visibilidad» que pre-determinaría nuestra consideración global de inteligibilidad de «lo real». En este sentido, habría que decir que adentrarnos en la elucidación de la naturaleza actuante del «imaginario social» entraña un propósito por hacer ostensible y manifiesto aquello que, por aproblematizado, resulta ser un tabú para una determinada sociedad. Por lo mismo, el ánimo que impulsa a una «sociología de los «imaginarios sociales»» será el de una liberación epistemológica de esos tabúes. Pues bien, admitido el axioma según el cual «lo real» es algo inaprensible como tal, la revitalización de la trascendencia sociológica del «imaginario social» surge de la asunción de que nuestro acceso al conocimiento de aquél se encuentra inevitablemente mediado por determinados «sistemas de representación simbólica» (Thomas, 1998: 16).

Primeramente diseccionaremos las directrices fundamentales, así como las divergencias de fondo, de los tres grandes marcos teóricos que, en esta dirección, han acometido en los últimos años una empresa destinada a poner de relieve, a nuestro juicio, la «invisibilidad social» antes mencionada, lo no-explícito de lo 
social, con sus consiguientes derivaciones como utillaje teórico para la compresión de la realidad social. Posteriormente, llevaremos a cabo una sistematización, un examen y un balance comparativo de ellas, buscando mostrar sus puntos de desencuentro nacidos de la axiomática de fondo sobre la que se apoyan, sus posibilidades y sus déficits sociológicos en ellas encerrados, así como sus posibles interconexiones epistemológicas. El desglose de los tres grandes marcos teóricos anteriormente apuntados se corresponde y nos exige, a título de delimitación conceptual, la asunción de una distinción de tres registros o niveles en la consideración y en la operatividad sociológica de los «imaginario(s) social(es)».

\section{NIVEL I: «IMAGINARIO SOCIAL» COMO «ARQUETIPO CULTURAL»}

La procedencia originaria de esta concepción del «imaginario social»_surge de la emblemática obra de Gilbert Durand, Las estructuras antropológicas de lo imaginario (1981), publicada a comienzos de los años sesenta del pasado siglo y prolongada posteriormente a través de distintas investigaciones en torno a la mitología, el arte o la literatura. La raigambre de saber a la que se adscribe esta concepción es la de una «antropología filosófica» con indudables resonancias en el campo de la «antropología cultural». Su visión del «imaginario social» tiene que ver con la profundización, precisamente desde lo que él bautizará como una «sociología de las profundidades», en torno a los pilares fundacionales y fundamentales sobre los que se sostiene una cultura. Su propósito será, entonces, el de una analítica de la civilización de alto alcance, en un proyecto global y totalizador. Por eso, a este primer registro o nivel del «imaginario social» bien podríamos denominarlo como nivel antropológico, con una fuerte carga de «significación cultural» condensada en torno a ciertas «imágenes primordiales». A grandes rasgos, la visión del «imaginario social» desprendida de la obra de Durand se apuntala sobre tres vértices:

A. El «imaginario social» está ligado a una exploración en torno a los latentes «elementos arquetípicos» sobre los que se sostiene una cultura. El término «arquetipo» haría referencia a «constantes antropológicas», recurrentes y transhistóricas, expresadas a través de ciertas figuras e imágenes mitológicas (Prometeo, Hermes, Dionisos.. ). Éstas actuarían a modo de principios originarios y fundantes, de pilares presupuestos, intangibles y globales, sobre los que se reposa y, al mismo tiempo, se articula — desde y a partir de una tensión originada del «politeísmo arquetipal»— la totalidad del ser y del sentir de una cultura. Cada civilización habría, entonces, revalorizado y entronizado un «modelo arquetipal» en detrimento de un eclipse de otros. Los «arquetipos» serían, pues, los «residuos semánticos de las vivencias del pasado filogenético, cuyas resonancias semánticas permanecen abiertas a vivencias colectivas futuras» (Sánchez Capdequí, 1999: 55). Indudablemente, el eco de la noción de «inconsciente 
cultural» de Carl Gustav Jung resuena sobremanera en esta concepción durandiana. Se trataría, en definitiva, del ««núcleo acorazado» que coincide con el corpus sagrado de los mitos», firmemente custodiado y aproblematizado, sobre el que asienta toda peculiaridad cultural (Durand, 1996a: 125). Su acepción más, diríamos, urbanizada sociológicamente sería aquella ligada a la consideración de «mito fundador» profundo o «arquetipo civilizatorio» sobre el cual pivotará por completo la significación del mundo y el acontecer práctico de los coparticipantes en un determinado nomos cultural.

B. La actuación del «imaginario social» está ligada a la persistente presencia, aunque casi siempre oculta o travestida, de la reubicación del mito en la contemporaneidad. De este modo, curiosamente, «lo más viejo», «lo originario», se ensamblaría y estaría constantemente operando (re-actualizándose) en el seno de «lo más nuevo», rompiendo con una concepción lineal de la temporalidad histórico-cultural instaurada por el progresismo y el historicismo reinantes en la segunda mitad del siglo XIX, propugnando, como contrapartida, una visión propiamente circular o, para ser más precisos, en espiral de ésta. «Lo inmemorial» se hallaría impreso, así, en «lo presente». Es más, la auténtica comprensión de «lo presente» pasaría por una mirada hacia «lo pasado», hacia «lo más inmemorial», tratando de desvelar «lo más originario» como esencialidad de lo que los contemporáneos son. La implicación sociológica más directa de lo anterior radicaría en que «lo empírico» (el fenómeno puntual y concreto motivo de estudio sociológico) cobra su auténtico significado a la luz de la latente pervivencia de un reservorio de «lo más remoto», de «lo inmemorial», proyectado éste reservorio sobre la especial fisiognomía simbólica de aquél. El «imaginario social» estaría, entonces, relacionado con ese permanente «fondo cultural», con esa persistente huella mítica fijada en «imágenes primordiales», que perseveraría en su actuación más allá de los avatares y de las complejas sinuosidades históricas; «algo que con (y a pesar) del correr del tiempo, permanece, porque no puede ser realizado, ni substituido» (Beriain, 1996: 278). Durand (1996b: 85-136) ha propuesto, a título de modelo heurístico, la noción de «cuenca (bassin) semántica» como metáfora explicativa del resurgimiento y reactualización de la presencia de «lo arquetípico» en elementos novedosos de una cultura, buscando dar cuenta, así, de la repetitiva persistencia de «lo más viejo» en el seno de «lo más nuevo», de «lo uno» en el interior de «lo múltiple». De este modo, cada «bassin semántico», cada concreta mentalidad cultural surgida en un determinado horizonte histórico, se anclaría y derivaría de un perenne («bassin semántico») primordial, sobre «el fondo inmemorial de una cultura, sobre un océano mítico primordial e insondable mucho más vasto» (Durand, 1996b: 88) que es, sin embargo, «re-inyectado» en lo más nuevo. De un modo u otro, la conclusión será que, en ningún caso, podemos escapar al dominio de «lo mítico», pese a la tan ilusoria como infructuosa tentativa de la racionalidad moderna de buscar afanosamente la depuración de éste. Cumpliéndose, así, el viejo y asertórico dictum frankfurtiano expresado en Dialéctica de la Ilustración, para Durand la razón moderna no sería otra cosa, en realidad, que un «mito fundante» más de entre aquellos constituti- 
vos de la tensión marcada por un insobornable «politeísmo arquetipal».

C. La genuina modalidad de saber propiciadora de un acercamiento a este invisible «fondo mítico», al «imaginario social», será aquella inspirada por una «hermenéutica de la cultura», desembocando finalmente la propuesta de Durand en un mitoanálisis cultural con un propósito fundamentalmente globalizador. Un mitoanálisis (una mythodologie) en donde la vía de mediación a la comprensión del «universo mítico-imaginario» característico de una trama cultural será el privilegiado dominio de «lo simbólico»; con un ánimo, además, de erigirse en una verdadera revolución epistemológica en el campo de las ciencias humanas y sociales. Para Durand (1968: 14-18), el símbolo, la fuerte carga de significación encerrada en ciertas «imágenes simbólicas» que una cultura ha apropiado como patrimonio propio, posibilitaría el acceso al «monde imaginale» (Corbin), a aquella oculta trascendencia que dona de sentido a toda especificidad cultural. En el símbolo se encarnaría, haciéndose visible, la invisibilidad mítica y arquetipal sobre la cual se ancla una determinada cultura. Y sólo una hermenéutica capaz de interpretar aquello que precisamente el símbolo encierra, proporcionaría el utillaje teórico necesario para la comprensión de las claves sobre las que una cultura descansa. Desde esta perspectiva, obviamente, la «invisibilidad» inscrita en lo social, las «realidades atmosféricas» que habitan en las concepciones socialmente objetivadas (León, 2001: 42), aquello que siendo base fundante de lo social permanece en la opacidad, apuntaría a un residuo inmemorial que, curiosamente, estaría permanentemente operando y proyectándose en lo más cotidiano.

En esta línea, uno de los grandes retos acometidos por la innovadora propuesta sociológica que Michel Maffesoli viene desarrollando en las tres últimas décadas ha sido precisamente aquella encaminada a mostrar la existencia de esa huella mítica, arquetipal, en el campo de lo más próximo, en el universo más cotidiano (Maffesoli, 1993b: 79-96). La tarea emprendida por Maffesoli ha consistido, básicamente, en urbanizar sociológicamente la antropología filosófica diseñada por Durand, su verdadero maestro y fuente de inspiración intelectual. Por eso, este autor insistirá en cómo «lo arquetípico» (»lo originario») se re-actualizaría y materializaría, tomando cuerpo y haciéndose presente, en modulaciones histórico-culturales, en fisiognomías que adoptan una fórmula estereotípica (Maffesoli, 1993a: 201-219); al unísono que, por ejemplo Anne Sauvageot (1987), hallará el verdadero magnetismo despertado por el mundo publicitario en este latente «sedimento arquetípico». La microscópica, aunque profunda, mirada en torno a El mito hoy de Roland Barthes (1999), o sea en torno a un abanico de fenómenos de la cultura contemporánea en donde este autor encuentra un residuo mítico, había ya revelado la recurrente persistencia de esa huella mítica en lo cotidiano. Barthes ha sabido ver la existencia de una cotidianidad poblada no de grandes «mitos sociogónicos» pero sí de una constelación de «micromitologías» con una fuerte capacidad de seducción colectiva. No obstante, dicho autor se acercara al mito desde una óptica diríamos peyorativa — por desmitologizante- - percibiendo simplemente el mito cotidiano como una ficticia huida, como 
una evasiva vía de escape, de lo cotidiano (como una deshistorización de éste), en sintonía con los presupuestos teóricos de una «sociología de lo cotidiano» tan al uso en la década de los setenta como la alentada por Henri Lefebvre o por la primera parte del itinerario intelectual de Jean Baudrillard. Habría, para Barthes, pues, algo de falsedad (en cuanto premeditada volatilización de «lo histórico») en todo mito cotidiano. No obstante, la perspectiva elegida por Maffesoli será otra. Bajo el evidente influjo de Durand, este autor encuentra en el mito fijado a la cotidianidad un ansia auténticamente transcendental por reimaginar o reencantar la existencia cotidiana. A este respecto, conviene dejar someramente apuntado que la sobrevivencia (sin un animo declaradamente crítico o peyorativo) de la lejanía mítica en el universo de la contemporaneidad había sido ya subrayada en la sugestiva originalidad de los estudios llevados a cabo por Morin (1972), (1981), (2001) en la década de los sesenta y setenta del pasado siglo, tomando como referencia para ello el «aura mágica» que envuelve al mundo cinematográfico en particular y a multitud de eventos de la cultura de masas en general; y, posteriormente, por Georges Balandier (1975), (1994) al desvelar éste cómo el elemento arcaico y su carga mítica latente será la subyacente causa explicativa de la adhesión y del magnetismo que el poder político suscita y reclama de sus seguidores. Por tanto, diríamos que, para Maffesoli, la eterna y transhistórica operatividad del mito proyectada en el escenario cotidiano no será vista en un tono, en absoluto, despreciativo, sino que, más bien, para él, obedecería a la misma sustancialidad del mito y, asimismo, a la sustancialidad de unas insobornables demandas antropológicas a las que históricamente el mito ha siempre procurado dar respuesta.

\section{NIVEL II: «IMAGINARIO SOCIAL» COMO «SIGNIFICACIÓN IMAGINARIA»}

La formulación más elaborada de este segundo nivel del «imaginario social» es, sin lugar a dudas, la propuesta llevada a cabo, a mediados de la década de los setenta del pasado siglo, por Comelius Castoriadis. Una propuesta eminentemente filosófica, circunscrita fundamentalmente al terreno de la ontología del ser social, aunque con notables derivaciones sociológicas. Castoriadis, en su obra cumbre La institución imaginaria de la sociedad (1983-1989), ha polemizado con las corrientes dominantes en las ciencia humanas y sociales del momento (básicamente: marxismo, estructuralismo, funcionalismo y psicoanálisis); surgiendo de esta polémica su particular concepción del «imaginario social». El nivel en donde este autor despliega su utillaje conceptual, sin perder un todavía notable grado de abstracción, no alcanza el registro de generalidad ni la pretensión de globalidad del pensamiento sociológico abierto por Durand. Así, la delimitación y los perfiles del foco de atención de su particular concepción del «imaginario social» se verán ahora involucrados en la historicidad, enmarcándose fundamentalmente en una analítica del modelo prototípico de sociedad capitalista. 
Su intención, pues, no será fijar su interés teórico en los «arquetipos civilizacionales» o míticos fundantes de una cultura, sino, más bien, en mostrar que el cómo una sociedad percibe y hace inteligible su mundo circundante, su especial manera de experienciar la vida cotidiana, así como también el modo en cómo aquella se autorrepresenta a sí misma, lleva todo ello implícito un componente más «imaginario» que propiamente «real». Por tanto, bien podríamos denominar a este segundo nivel del «imaginario social» como nivel ontológico-sociológico, perdiendo, en relación al anterior nivel, una evidente densidad antropológico-cultural, derivada de su desligación con respecto a una dimensión transhistórica y arquetipal, pero, a cambio, ganando en notorias posibilidades como utillaje más propiamente sociológico para interpretar fenómenos más locales de la realidad social. Y este componente imaginario, que él llamará «significaciones imaginarias» de la sociedad, será la instancia que configurará y estructurará, en sentido amplio, la manera de ser diferencial de una sociedad en sus diferentes parcelas y ubicaciones.

A grosso modo y para lo que nos ocupa, su concepción del «imaginario social» bien podría resumirse del siguiente modo:

A. La singularidad de cada sociedad obedece a la existencia, digamos que propiamente ideacional, de unas «significaciones centrales», de unas «articulaciones últimas», que actuarían como «esquemas matriciales» organizadores de la significación de la totalidad de su mundo. De esta forma, el «imaginario social», al modo en cómo es contemplado por Castoriadis, será un recurso teórico inigualable para dar cuenta de cómo se mantiene firmemente unida una sociedad por medio de un cemento colectivo (el «imaginario social»), para indagar en las claves explicativas de por qué existe un homogéneo Nosotros colectivo en torno al cual los integrantes de un conjunto social, en su complementariedad, se identifican y en torno al cual se adhieren (Castoriadis, 1983: 256-257). El «imaginario social» se expresará, tomará cuerpo, por otra parte, en el específico dominio de «lo simbólico», encarnándose en «símbolos institucionalizados» con una fuerte carga grupal tanto a nivel sentimental como afectivo, prologando y extrayendo, así, todas las posibles consecuencias encerradas en la vieja concepción de la religión de Durkheim (1982), según la cual el símbolo (totémico) condensaba y representaba el «espíritu de grupo» bajo una forma de unidad material. De ahí que el «imaginario social» se hubiese erigido en una herramienta teórica especialmente sugerente a la hora de analizar el papel de las «representaciones colectivas» como garantizadoras de la pervivencia de construcciones identitarias (Beriain, 1996: 278-312). Dado que, además, como hemos dejado anteriormente indicado, el «imaginario social» de Castoriadis es intrínsecamente refractario a su encorsetamiento en una clave conceptual o definición al uso, el acceso al modo en cómo éste se nos revela, nos habla, deberá adoptar una vía diferente: la de la metáfora y, por ende, la de la retórica (que no aquella habitualmente transitada por la epistemología) (Lizcano, 2006: 60-71). Para Lizcano, será precisamente del resultado de esta simbiosis entre 
«imaginario social» y metáfora de donde éste podría extraer una mayor utilidad metodológica para la ciencia social.

B. Las «significaciones imaginarias» de la sociedad institucionalizan una manera de presentarse el mundo para los individuos a ellas adheridos. La sociedad, a través de su singular «imaginario social», tendrá la facultad de modelar culturalmente la naturaleza en su conjunto, otorgando una «significación» a su particular mundo y definiendo lo válido, lo legítimo y lo deseable para cada sociedad. Las similitudes con el concepto de «universo simbólico» acuñado desde la sociología fenomenológica por Peter Berger y Thomas Luckmann (1986) son evidentemente notorias. Para una determinada sociedad, su realidad, en sus diferentes aspectos y con las diferentes «cosas» que la componen, es «realidad» y las cosas «Son» «en la medida en que encarnan, figuran o presentifican «significaciones sociales». Las cosas sociales son lo que son gracias a las significaciones que figuran, inmediata o mediatamente, directa o indirectamente» (Castoriadis, 1989: 307). A nivel sociológico, el papel atribuido a la dimensión empírica no será ahora el de una materializada y concreta proyección de «lo originario», sino, más bien, el de un indicio manifiesto en donde aquello que no se deja ver (ahora concebido como constructo ideacional e histórico) se nos dejaría translucir simbólicamente. La «representación social», según Castoriadis, se encuentra, entonces, no como un simple «agregado» independiente de «lo real», sino, por el contrario, formando una parte esencial e implicada en «lo real»; pero no distanciada aquella, en términos dicotómicos, respecto de éste. La actividad general de un modelo de sociedad sería impensable sin la operatividad de las «significaciones imaginarias», del mismo modo que éstas necesitarían materializarse, ineludiblemente, en distintas parcelas y actividades sociales. Por eso, las «significaciones imaginarias» no se dejan aprehender, no son percibidas como tales, manteniéndose en la «invisibilidad» de lo social; únicamente podrán ser atisbadas retrospectivamente en su implicación sobreañadida a las cosas. «La institución de la sociedad — dirá Castoriadis- es lo que es y tal como es en la medida en que materializa un magma de significaciones imaginarias sociales, en referencial al cual y sólo en referencia al cual, tanto los individuos como los objetos pueden ser aprehendidos e incluso pueden simplemente existir; y este magma tampoco puede ser dicho separadamente de los individuos y de los objetos a los que da existencia» (Castoriadis, 1989: 307).

C. Cada modelo de sociedad instituye, por medio de sus particulares «significaciones imaginarias», un mundo que aparecerá como evidente, connaturalizado y aproblematizado, de modo que «el mundo» pasará a ser «su mundo» institucionalizado. Como es obvio y a tenor de lo dicho, se oculta, se conserva implícito, que «el mundo» para aquellos que coparticipan en un modelo de sociedad determinado lo es, básicamente, como fruto del papel creador ex nihilo de las «significaciones imaginarias». De ahí que la posición de Castoriadis aboque, sin una sin embargo transparente formulación a este respecto por su parte, al papel del «imaginario social» como elemento ideacional constructor de la realidad social. De mayor interés sociológico si cabe es que Castoriadis (1998: 113- 
123) hubiera distinguido posteriormente, en este sentido y a título metodológico, las «significaciones imaginarias centrales» (matrices globales de significación) y las «significaciones imaginarias segundas» —derivadas de las anteriores y en una íntima conexión articulada con aquellas (trabajo, familia, temporalidad, leyes, etc.) - en un modelo de sociedad, eso sí, en donde la global «significación» del mundo es irradiada y vertebrada en torno y desde las primeras. Indudablemente, esta distinción logra reforzar la competencia del modelo de Castoriadis para su posible aplicación en un dominio más propiamente sociológico (y menos filosófico) y en una variada constelación de espacios sociales, tal como ha puesto de relieve Daniel Cabrera, al aplicarlo con notable acierto al estudio del universo concreto de las nuevas tecnologías (Cabrera, 2006).

\section{NIVEL III: «IMAGINARIO SOCIAL» COMO «CONSTRUCTOR DE REALIDAD(ES) SOCIALES»}

La definitiva consolidación del «imaginario social» como recurso epistemológico y metodológico para el análisis de la realidad social viene dada a raíz de la obra desarrollada desde hace más de una década por Juan Luís Pintos. Podríamos decir que Pintos logra dotar a la noción de «imaginario social» de una operatividad estrictamente sociológica de la cual ésta anteriormente adolecía (Coca y Valero, 2009: 151-152). Para ello, insertará dicha noción en el marco teórico de la «Teoría de Sistemas» luhmanniana e intentará, asimismo y sobremanera, ligarla a la inherente facultad atesorada en el «imaginario social» para configurar y estructurar - en suma para crear - realidades, traspasando, no obstante, las directrices formuladas desde el imperialismo del signo lingüístico propugnado desde la semiótica. Su objetivo se encaminará, entonces, a explotar sociológicamente la vertiente constructivista propia del «imaginario social». Para ser más precisos, desde su óptica, el mayor interés de los «imaginario(s) social(es)» es su irremplazable fecundidad para crear realidades; dado que a Pintos le interesará fundamentalmente poner de relieve dos aspectos:

a) La potencial pluralidad de versiones que acoge la realidad (la realidad no es una sino múltiple).

b) La dimensión, también plural, del «imaginario social», pero ahora en lo concerniente a su actividad en diferentes plexos de la vida cotidiana.

Por eso, su perspectiva bien podría ser catalogada de nivel sociológico constructivista.

A grandes rasgos, su propuesta podría ser sintetizada del siguiente modo:

A. Un objetivo destinado a ligar el decisivo papel sociológico asignado a los «imaginario(s) social(es)» con una «teoría de la observación» de raigambre constructivista, amparándose, para ello, no solamente en la epistemología luh- 
manniana, sino, también, en los modelos epistemológicos exportados desde el campo de la biología a las ciencias sociales por Varela (1996) y Maturana (1984); incidiendo ambos en que el conocimiento de la realidad es indisociable del particular modo en cómo el «sujeto» se dirige a ésta y derivando, así, en la conclusión de una «teoría de la observación» de acento constructivista. Pintos partirá de un presupuesto de fondo evidentemente determinado por la ontología constructivista luhmanniana, según la cual la «realidad», y más en concreto la «realidad social», no es otra cosa que el resultado de las «distinciones» realizadas desde observadores que operan con unas particulares (y siempre parciales) «observaciones». Desde este ángulo teórico, aquello, en suma, considerado como «realidad» es indisociable del modo en cómo ésta se presenta para un determinado «sujeto» que la «observa», que accede a ella. En este sentido, el papel de los «imaginario(s) social(es)» adquiriría un estatuto metodológico primordial, puesto que serían aquellos instrumentos a través de los cuales se nos haría inteligible y perceptible de modo peculiar «la realidad», convirtiéndose en los recursos mediante los cuales crearíamos «evidencias sociales» (una concreta realidad), a partir, eso sí, de distintos «esquemas observacionales». Los «imaginario(s) social(es)» configurarían, pues, aquello que será asumido como «la realidad social», teniendo como función primaria «la elaboración y distribución generalizada de instrumentos de percepción de la realidad social construida como realmente existente» (Pintos, 1995: 11); o, como dirá Pintos en otro contexto, serían «aquellos esquemas, construidos socialmente, que nos permiten percibir algo como real, explicarlo e intervenir operativamente en lo que cada sistema social se considere como realidad» (Pintos, 2003: 164).

B. La operatividad de los «imaginario(s) social(es)» se nos revelaría, para él, desde el esquema dicotómico relevancial opacidad. Un determinado «imaginario social», al operar mediante una «distinción», haría relevante una concreta manera de ser de la realidad, omitiendo, de este modo (o lo que es similar manteniendo en el ocultamiento, o en la opacidad), otras posibles manera de ser - también plausibles - a través de las cuales se nos podría hacer presente esa misma realidad. La presencia de «lo empírico», a tenor de esta versión lógicamente más sociológica del «imaginario social», se contemplaría como punto de referencia a partir del cual abriríamos la interrogación en torno a «lo ausente»; es decir, en torno a aquello que extralimitaría, que quedaría fuera, del umbral de lo definido institucionalmente como «realidad». Por tanto, «lo ausente», «lo invisible»— en suma la opacidad — de «lo social» no obedecerá, en modo alguno, a ningún registro que debiera verse en términos diacrónicos (»lo más originario» oculto en «lo presente»), sino, más bien, sincrónicos (la imposibilidad de que un mismo «observador» pueda simultanear al mismo tiempo diferentes «observaciones»).

Como resultado del reconocimiento de la quiebra de cualquier monopolio de «definición unitaria» de la realidad (patrimonio en modelos de sociedad precedentes de las instituciones religiosas y/o políticas), uno de los detonantes característicos de las «sociedades complejas» (las derivadas de la modernidad) será la 
prevalencia de una exacerbada competencia entre distintas instituciones, medios de comunicación o estrategias de mercado por adueñarse de una «definición hegemónica de la realidad» (Gramsci); o, para decirlo en la terminología procedente de Gothar Günther y que gusta de utilizar Pintos, las sociedades actuales serían sociedades «policontexturales». Pero además, este autor acometerá el desafío teórico de formular una metodología adecuada para «visualizar» la operatividad de los «imaginario(s) social(es)», sacando a éstos de la «invisibilidad», así como de sus transformaciones o modificaciones en el curso del tiempo. En esta tarea, apelará al marco de pensamiento diseñado desde la «Sociocibernéti$c a »$, a las técnicas sociológicas apoyadas sobre «observaciones de segundo orden» y basadas en los desarrollos teóricos más recientes de la «cibernética segunda». En síntesis, la «observación de segundo orden» sería aquella que «observaría» las distintas «observaciones de primer orden», explicitando, entonces, las diferentes relevancias/opacidades manejadas en las construcciones de realidad llevadas a cabo en las «observaciones de primer orden» y a partir de los consiguientes «imaginario(s) social(es)».

C. La concepción del «imaginario social» propuesta por Pintos se desmarca de las dos anteriores. No tiene como objetivo presentarse como el «arquetipo fundante» y transhistórico de una cultura (nivel I), ni tampoco como «significación imaginaria» desde la cual pensamos, sentimos y asumimos el mundo, pero de la cual difícilmente podríamos distanciarnos o hacer «epojé» de ella (nivel II); aunque con esta última versión habría ciertos puntos de confluencia aun por resaltar.

Las diferencias esenciales de la visión de Pintos en relación a las dos anteriores consistirían en que:

a) Le interesa sobremanera concebir y estudiar el «imaginario social» en lo que éste tiene de «representación social» de carácter transitorio, cambiante y más apegado a la historicidad.

b) Le interesa una «realidad imaginaria» en lo que ésta tiene de elaborada desde fuera (dispositivos de creación de «sentido») y no en lo referente a su faceta como emanación antropológica desde dentro o como «instituyente radical» que diría Castoriadis (Baeza, 2000: 138).

c) Le interesa el «imaginario social» en su faceta de legitimación de realidad(es) sociales y no en aquella ligada a los procesos de auto-transformación de la sociedad (Pérez Rubio, 2009: 297).

Desde la opción adoptada por Pintos, el análisis gana en una evidente fertilidad sociológica (fundamentalmente epistemológica y metodológica) que pierde, sin embargo, en, por así decirlo, pretensión antropológica. Y precisamente por ello, la formulación de Pintos parece la más acorde para el estudio fundamentalmente de los «imaginario(s) social(es)» actuantes tanto en el universo mediático, en el régimen de imaginería que, al decir de Gerard Imbert, sería «una 
visibilidad que saturaría por completo el espacio de la comunicación» (Imbert, 1992: 147), como en los discursos elaborados y transmitidos desde distintos marcos institucionales (político, científico, publicitario o religioso).

\section{A TÍTULO DE CONCLUSIÓN: BALANCE PROVISIONAL ENTRE NIVELES: SISTEMATIZACIÓN, INTERSECCIONES Y CONTINUISMO EN LAS «REPRESENTACIONES SOCIALES»}

Elucidar y escudriñar lo «no explícito», la «invisibilidad», de lo social es algo proclive a la generación de formulaciones teóricas vagas y a confusionismos intelectuales. $\mathrm{Al}$ movernos en un terreno intrínsecamente reacio o resistente a una sujeción no sólo empírica sino incluso conceptual, es fácil caer en una tentativa de utilización de nociones terminológicas sin una previa aclaración de su auténtico uso sociológico y sin una obligada delimitación nítida de sus perfiles ontológicos o/y epistemológicos.

Por ello, es conveniente aclarar las peculiaridades de cada nivel que hemos diferenciado, sus puntos de encuentro y el posible continuиm entre éstos; con el ánimo de poner de relieve las diferentes resonancias e implicaciones que de todo ello se derivaría para la ciencia social. En otros términos, de cada uno de los $n i$ veles previamente distinguidos en la visión del «imaginario social» se desprenderá, más allá de las concomitancias de fondo, una manera peculiar de concebir no solamente el papel sociológico asignado a las «representaciones sociales» sino, también, a la propia perspectiva de reconsideración del hacer sociológico.

Utilizaremos el cuadro a continuación indicado para desglosar una factible sistematización conjunta de las «representaciones sociales» y el «imaginario social»:

\begin{tabular}{|l|l|l|l|l|}
\hline & $\begin{array}{c}\text { Dimensión } \\
\text { Ontológica }\end{array}$ & $\begin{array}{c}\text { Dimensión } \\
\text { epistemológica }\end{array}$ & $\begin{array}{l}\text { Horizonte de } \\
\text { operatividad }\end{array}$ & $\begin{array}{c}\text { Campo de } \\
\text { aplicación }\end{array}$ \\
\hline Nivel I & $\begin{array}{l}\text { Arquetípica } \\
\text { transhistórica })\end{array}$ & $\begin{array}{l}\text { Antropología } \\
\text { Hermenéutica } \\
\text { y Simbólica }\end{array}$ & $\begin{array}{l}\text { Macrolmicro- } \\
\text { mitologías } \\
\text { contemporáneas }\end{array}$ & $\begin{array}{l}\text { Socio- } \\
\text { antropología } \\
\text { cultural }\end{array}$ \\
\hline Nivel II & Fenomenológica & $\begin{array}{l}\text { Sociología } \\
\text { Simbólical } \\
\text { Metafórica }\end{array}$ & $\begin{array}{l}\text { Análisis } \\
\text { institucional }\end{array}$ & $\begin{array}{l}\text { Sociología } \\
\text { del } \\
\text { conocimiento } \\
\text { (científico)/ } \\
\text { cultura }\end{array}$ \\
\hline Nivel III & Constructivista & Sociocibernética & $\begin{array}{l}\text { Mass-media, } \\
\text { analítica del } \\
\text { discurso }\end{array}$ & $\begin{array}{l}\text { Sociología de la } \\
\text { comunicación/ } \\
\text { cultura }\end{array}$ \\
\hline
\end{tabular}

EMPIRIA. Revista de Metodología de Ciencias Sociales. N. ${ }^{\circ}$ 20, julio-diciembre, 2010, pp. 87-108. ISSN: $1139-5737$ 
De acuerdo con este cuadro, podemos percatarnos de la tipología de actuación sociológica de las «representaciones sociales». Tipología que, como toda tipología, admitirá unas comprensibles zonas de intersección e interconexión entre los tres niveles, no limitándose a contemplar éstos como compartimentos absolutamente diferenciados y encapsulados. El valor heurístico del cuadro anteriormente desglosado se debiera complementar, asimismo, con una triple dimensión entrelazada de las «representaciones sociales»: a) Gradación. b) Unidad/Multiplicidad. c) Continuismo.

a. Gradación: Cada nivel previamente admitido se correspondería con una específica densidad o espesura en la gradación, en lo que ésta tiene de pretensión de fundamento de globalidad, de las «representaciones sociales» y, consiguientemente, con una operatividad sociológica bien distinta. El nivel III focalizaría su atención en el grado de las «representaciones sociales» en donde éste no tendría como intención salirse del campo propio de la historicidad y, en consecuencia, de un espacio de aplicación siempre contextual. El nivel II, limitando en su gradación con el nivel anterior, implicaría un mayor grado de densidad cultural, con una tendencia a fijar su atención sobre las «representaciones sociales» de mayor globalidad, sobre los todavía plurales y contextuales constructos ideacionales centrales sobre los que se articula una sociedad. Finalmente, el nivel I se ocuparía de las «representaciones sociales» de mayor gradación, cuya atención se fijaría sobre la globalidad cultural en su conjunto.

b. Unidad/Multiplicidad: El tránsito entre los distintos niveles (del nivel III al nivel I) entraña una paulatina disminución del espectro de extensión de las «representaciones sociales». El nivel III se caracterizaría por una absoluta fragmentación, heterogeneidad y pluralidad de las «representaciones sociales» relativa a su visualización en una múltiple gama de espacios sociales. El nivel II implicaría ya una notable reducción - reducción encaminada a una selección de lo básico o nuclear - en la heterogeneidad y en la extensión del número de «representaciones sociales». El nivel I significaría, finalmente, una reducción a la unicidad de las «representaciones sociales», entendida ésta reducción como búsqueda de ese principio unitario, homogeneizador, fundante y nuclear de una cultura.

c. Continuismo: La relación entre los tres niveles indicados puede verse, en realidad, como un continuum desde una mayor concreción (nivel III) a una mayor generalidad (nivel I). El nivel III fija su atención en las «representaciones sociales» más locales, mientras el nivel I lo haría en las más generales. Utilizando una metáfora aclarativa procedente del campo tectónico podríamos decir que las «representaciones sociales» de nivel III se corresponderían con la capa más epidérmica de la «representación social», las «representaciones sociales» de nivel II con la capa intermedia, y las «representaciones sociales» de nivel I con la capa nuclear (núcleo básico de la «representación social»). Aunque, conviene tenerlo presente, entre las tres capas se produzca una natural mediación e interconexión de fondo permanente. 


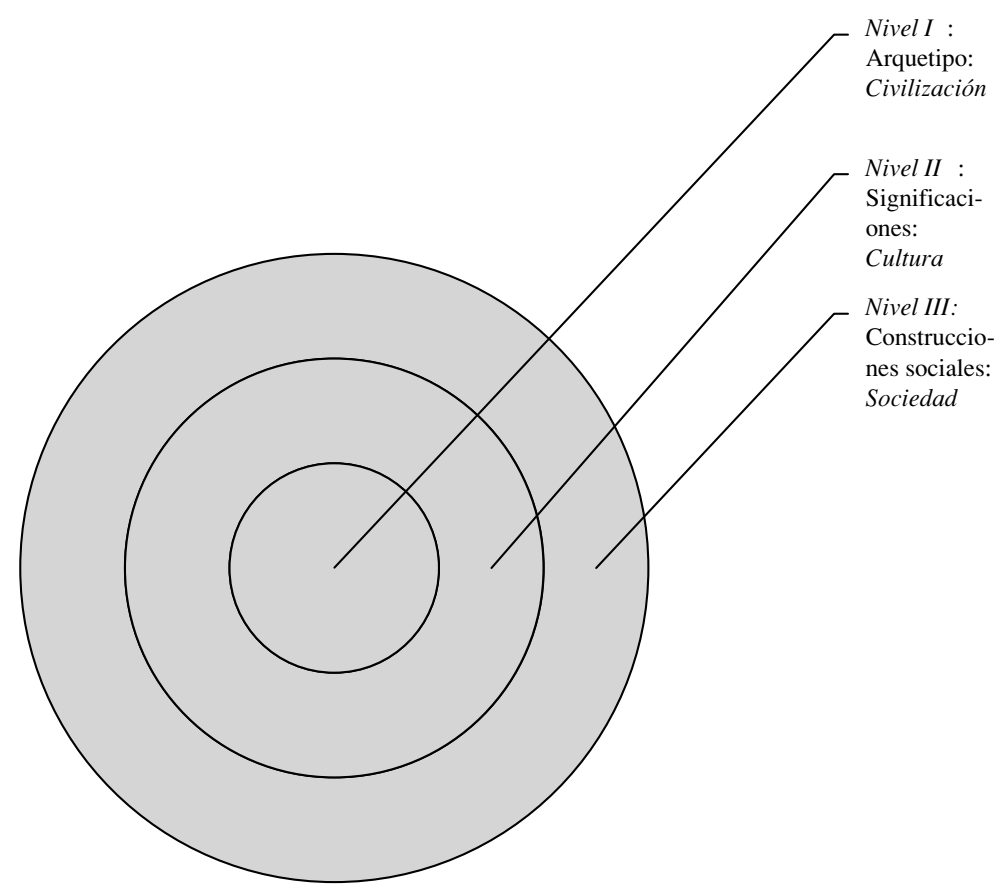

A la luz del gráfico arriba indicado, se nos muestran las intersecciones e interrelaciones entre los tres niveles de la «representación social» anteriormente desglosados. Como podemos observar, una «representación social» del nivel III mantiene un continuismo o remite a una de nivel II y, a su vez, ésta a otra de nivel I. El nivel I existe en el nivel II, y éste, por su parte, en el nivel III. Por ejemplo, «representaciones sociales» impresas en la práctica totalidad de fenómenos sociales de la vida cotidiana, tales como las de la violencia, el género o el trabajo, estarían incluidas en el nivel III; aunque, en función del alcance ontológico atribuido a nuestro análisis, podríamos acceder asimismo, a través de las «representaciones sociales» anteriores, a los niveles I y II sobre-implicados en ellas. Todo dependerá, en definitiva, de la dimensión más contextual o más global en donde al investigador le interese ceñir el objeto de interés de la operatividad de las «representaciones sociales»; o, dicho de otro modo, donde éste ubique el límite para la generalidad de su análisis. Por este orden, las tres dimensiones de la «representación social» que pudieran ser objeto, entonces, de un abordaje analítico serían: (nivel III: La Sociedad / nivel II: La Cultura / nivel I: La Civilización).

Conviene señalar que nuestro esfuerzo por profundizar en el logro de una provisional tentativa metodológica de esquematización de los distintos niveles de operatividad sociológica del «imaginario social» concuerda, en buena medida, con la reciente propuesta de Baeza (2008: 477-492). Para éste, desde una inspi- 
ración claramente fenomenológica, los niveles que hemos denominado como nivel I y nivel II se corresponderían, en su conjunto, con lo que él llamará «imaginario radical», mientras que el nivel III se correspondería con lo que llama «imaginario periférico», reconociendo, en efecto, la interrelación y la fuerte dependencia del segundo con respecto al primero. Asimismo, Baeza subrayará, en sintonía con nuestra elaboración teórica, el fundamento «arquetípico» e inconsciente del «imaginario radical», así como el nivel «discursivo-consciente» en donde se movería el «imaginario periférico». El ánimo impulsor de ambas propuestas será, no obstante, similar, a saber: la necesidad de examinar la plural estructura operativa de las «representaciones sociales» con sus consiguientes resonancias metodológicas, siendo esto revelador, por otra parte, de la acuciante demanda actual por clarificar el papel metodológico asignado a las «representaciones sociales» en el marco de una sociología que se declare postempirista.

Para concluir, recurriremos a un ejemplo significativo -el del Trabajopara ilustrar lo anterior. Un ejemplo, en realidad, paradigmático, dado que resulta de utilidad como patrón común para abordar, desde esta óptica, una variada gama de «representaciones sociales» actuantes en el universo cotidiano. La especificidad de la «representación social» del Trabajo en un concreto modelo social occidental (la dimensión de La Sociedad) podría ser abordada desde el nivel III, es decir, como una construcción social de la realidad de naturaleza discursiva y generada históricamente desde determinadas instancias, bien sean éstas políticas, económicas o mediáticas. Pero, a su vez, cuando nos adentramos en la cosmovisión cultural propia de Occidente (la dimensión de La Cultura) en donde el Trabajo ocupa el vértice angular y articulador de la totalidad de la vida social, en cómo éste impregna por completo los distintos plexos en los que se entreteje la vida de las personas y en cómo éste deviene, en última instancia, un decisivo signo de sociabilidad o de integración social, nos ubicaríamos en el nivel II. Evidentemente, la «representación social» del Trabajo del nivel III no podría darse sin una apoyatura o sostén en la «representación social» del Trabajo nivel II, de manera que la «representación social» del Trabajo del nivel II estaría proyectada e irradiada, en una suerte de flujo constante, sobre la «representación social» del Trabajo del nivel III. Asimismo, cuando ahondamos todavía más en el fundamento antropológico-cultural que, en Occidente, marca el rumbo de la concepción de la relación que, a través del Trabajo, establece el hombre con la naturaleza (la dimensión de La Civilización), descubrimos un sólido e incuestionable «mito fundante» en el que se ampara esta relación, a saber: una actitud de dominio y explotación, condensada metafóricamente en la figura arquetípica de Prometeo. Nos ubicaríamos, entonces, en la «representación social» del Trabajo de nivel I. La «representación social» del nivel II (y por ende la de nivel III) no serían factibles, pues, sin la «representación social» de nivel I. La «representación social» del nivel I se proyectaría e irradiaría, en un flujo también constante, sobre las «representación social» de los niveles II y III. De modo que, en definitiva, los niveles II y III estarían preñados del nivel I, y, a su vez, el nivel II lo estaría del nivel I y el nivel III del nivel II. 


\section{BIBLIOGRAFÍA}

Adorno, Th. y HorkHeIMER, M. (1994): Dialéctica de la Ilustración, Madrid, Trotta.

AleXANDER, J. C. (2000): Sociología Cultural: Clasificación en sociedades complejas, Barcelona, Anthropos.

ANDERSON, B. (1993): Comunidades imaginadas, México, FCE.

BACHELARD, G. (1997): La formación del espíritu científico, Madrid, Siglo XXI.

- (1998): Poética de la ensoñación, México, FCE.

BAEZA, M. A. (2000): Los caminos invisibles de la realidad social, Santiago de Chile, RIL.

- (2008): Mundo real, mundo imaginario social. Teoría y práctica de sociología profunda, Santiago de Chile, RIL.

BALANDIER, G. (1974): Antro-pológicas, Barcelona: Paidos.

- (1975): Antropología política, Barcelona: Gedisa.

- (1994): El poder en escenas, Barcelona, Paidos.

BARTHES, R. (1999): Mitologías, Madrid, Siglo XXI.

Berger, P. (1981): Para una teoría sociológica de la religión, Barcelona, Kairós.

BERGER, P. y LuCKMANN, Th. (1986): La construcción social de la realidad, Buenos Aires, Amorrortu.

BERIAIN, J. (1996): La integración en las sociedades modernas, Barcelona, Anthropos.

BERGSON, H. (1996): Las dos fuentes de la moral y de la religión, Madrid, Tecnos.

Bloor, D. (1998): Conocimiento e Imaginario Social, Barcelona, Gedisa.

Bourdieu, P. (2001): El sentido práctico, Madrid, Taurus.

CABrera, D. (2006): Lo imaginario y lo tecnológico, Buenos Aires, Biblos.

CARRETERO, E. (2008): «Lo imaginario social. El entrejuego paradójico de la creación y de la institución social», en Las posibilidades de los imaginarios sociales, J. R. COCA (ed.), Barcelona, Serbal, pp. 11-38.

CAssirer, E. (1972): La philosophie des formes symboliques, París, Minuit, 3 vols.

CASTORIADIS, C. (1983-1989): La institución imaginaria de la sociedad, Barcelona, Tusquets, 2 vols.

- (1999): Figuras de lo pensable, Madrid, Cátedra.

CocA, J. y VALERO, J. (2009): «Relevancia (bio)tecnológica del planteamiento pintosiano sobre la teoría de los imaginarios sociales», en Sociologías en los márgenes. Homenaje al Profesor Juan Luís Pintos de Cea Naharro, J. R. COCA y E. CARRETERO (eds.), Huelva, Le Hergué, pp. 145-159.

DíAz, E. (1996), La ciencia y el imaginario social, Buenos Aires, Biblos.

Douglas. M. (1973): Pureza y peligro. Un análisis de los conceptos de contaminación y tabú, Madrid, Siglo XXI.

DuRAND G. (1968): La imaginación simbólica, Buenos Aires, Amorrortu.

- (1981): Las estructuras antropológicas de lo imaginario, Madrid: Taurus.

- (1996a): «Le social et le mythique. Pour une topique sociologique», en Champs de L'imaginaire, Grenoble: ELLUG. Université Stendhal, pp. 109-157.

- (1996b): Introduction à la Mythodologie, París, Albin Michel.

- (2000): Lo imaginario, Barcelona, Ediciones del Bronce.

DURKHEIM, E. (1982): Las formas elementales de la vida religiosa, Madrid, Akal.

- (2000): Sociología y filosofía, Madrid, Miño y Dávila Editores.

FoucAult, M. (1968): Las palabras y las cosas. Una arqueología de las ciencias humanas, Madrid, Siglo XXI. 
GADAmer, G. (1977-2002): Verdad y Método, Salamanca, Sígueme, 2 vols.

GEERTZ, C. (1990): La interpretación de las culturas, Barcelona, Gedisa.

GIROLA, L. (2007): «Modernización, Modernidad y después... Las ciencias sociales en América Latina y la construcción de los imaginarios de la modernidad», en Modernidades. Narrativas, mitos e imaginarios, L. GIROLA y M. OLVERA (Coords.), Barcelona, Anthropos, pp. 61-103.

Godelier, M. (1990): Lo ideal y lo material, Madrid, Tecnos.

IMBERT, G. (1992): Los escenarios de la violencia, Barcelona, Icaria.

JOAS, H. (1998): El pragmatismo y la teoría de la sociedad, Madrid, CIS.

JODELET, D. (1986): «La representación social: fenómeno, concepto y teoría», en Psicología Social. II, S. MOSCOVICI (ed.), Barcelona, Paidos, pp. 470-494.

KuHN, Th. (1986): La estructura de las revoluciones científicas, México, FCE.

LEÓn, E. (2001): De arquetipos y filias, Barcelona, Anthropos.

LizCANO, E. (1993): Imaginario colectivo y creación matemática, Barcelona, Gedisa.

- (2006): Metáforas que nos piensan, Madrid, Bajo Cero.

MAFFESOl, M. (1993a): La contemplation du monde, París, Grasset.

- (1993b): El conocimiento ordinario, México, FCE.

Maturana, H. (1984): El Árbol del conocimiento: las bases biológicas del conocimiento humano, Barcelona, Debate.

Morin, E. (1972): Les Starts, París, Seuil.

- (1981): Le sprit du temps, París, Livre du Poche.

- (2001): El cine o el hombre imaginario, Barcelona, Paidos.

MoscovicI. (1961): La psychanalyse, son image et son public, París, PUF.

- (1989): «Des représentations colectives aux represéntations sociales: élements pour une histoire», en Les représentations sociales, D. JODELET (dir.), París, PUF, pp. 79-103.

PÉrez Rubio, A. M. (2009): «De los Imaginarios a las Representaciones Sociales: notas para un análisis comparativo», en Sociologías en los márgenes. Homenaje al Profesor Juan Luís Pintos de Cea Naharro, J. R. COCA y E. CARRETERO (eds.), Huelva, Le Hergué, pp. 285-302.

PinTos, J. L. (1995): Los imaginarios sociales. La nueva construcción de la realidad social, Madrid, Cuadernos Fe y Secularidad/Sal Terrae.

- (2003): «Los imaginarios sociales del delito. La construcción social del delito a través de las películas (1930-1999)», en Cornelius Castoriadis. La pluralidad de los imaginarios sociales de la modernidad, C. SÁNCHEZ CAPDEQUÍ (Coord.), Barcelona, Anthropos, pp. 161-176.

RoRTY, R. (1995): La filosofía y el espejo de la naturaleza, Madrid, Tecnos.

SÁNCHEZ CAPDEQUí, C. (1999): Imaginación y sociedad. Una hermenéutica creativa de la cultura, Madrid, Tecnos.

Sauvageot, A. (1987): Figures de la publicité, figures du monde, París, PUF.

SchÜTZ, A. (1962): El problema de la realidad social, Buenos Aires, Amorrortu.

TAYLOR, Ch. (2006): Imaginarios sociales modernos, Barcelona, Paidos.

TACUSSEL, P. «La sociologie interprétative. Un tournant postempiriste dans les sciences humaines en France», en La sociologie française contemporaine, J. M. BERTHELOT (ed.), París, PUF, pp. 117-125.

Thomas, J. (1998): «Introduction», en Introduction aux méthodologies de l'imaginaire, J. Thomas (dir.), París, Ellipses, pp. 15-21.

Thompson, J. B. (1992): Ideology and Modern Culture. Critical Social Theory in the Era of Mass Communication, Cambridge, Polity Press. 
VAREla, F. (1996): Conocer. Las ciencias cognitivas, Barcelona, Gedisa.

VÉDRINE, H. (1990): Les grandes conceptions de l'imaginaire de Platón à Sartre et Lacan, París, Livre de Poche.

\title{
RESUMEN
}

El presente trabajo pretende mostrar, en líneas generales, las diferentes implicaciones epistemológicas para la ciencia social resultantes del reconocimiento de los distintos modos de operatividad sociológica conferidos a las «representaciones colectivas», y, en especial, al campo del «imaginario social». Para ello, primeramente, se preocupa de desglosar los marcos teóricos actuales más destacados en la consideración del «imaginario social», enfatizando como éstos estarían revelando una axiomática epistemológica diferenciada. Finalmente, sistematiza los distintos niveles albergados en el uso del «imaginario social», estableciendo sus interrelaciones y proponiendo un balance comparativo entre ellos, de lo que se deduciría un horizonte de aplicabilidad y un campo de actuación sociológicos también distintos.

\section{PALABRAS CLAVE}

Representaciones sociales, Imaginario social. Epistemología, Hermenéutica, Constructivismo.

\begin{abstract}
The present work tries to show, in main lines, the different methodological and epistemological implications for social science resulting from the recognition of the different conferred ways from sociological operativity from the «collective representations», and especially from the «imaginary social». For it, firstly, it one worries to detach to the present theoretical marks more outstanding in the «imaginary» consideration of the social one, emphasizing as these would be revealing axiomatic an epistemologic one differentiated. Finally, it systematizes the different levels lodged in the «imaginary social», establishing his interrelations and proposing a comparative balance among them, than it would be deduced a horizon of applicability and also different a sociological field of action.
\end{abstract}

\section{KEY WORDS}

Social representations, Imaginary social. Epistemology, Hermeneutics, Constructivism 